\title{
Management of Non-vital Maxillary Central Incisors with Open Apices by MTA Plugging
}

\author{
MAH SHEIKH $^{\mathrm{a}}$, AK SHEIKH ${ }^{\mathrm{b}}$, KAMRUNNAHAR $^{\mathrm{c}}, \mathrm{S}^{\text {PARVEEN }}{ }^{\mathrm{d}}$
}

\begin{abstract}
Summary:
The major challenge of performing root canal treatment in an open apex pulp-less tooth is to obtain a good apical seal. An 11 year old boy was presented with pain in his upper anterior teeth. On clinical examination both the maxillary central incisors revealed slight discoloration and fracture of the crown. Radiographic evaluation revealed radiolucency and open apices of both central incisors. Apexification with MTA apical plug was carried out before obturation with gutta-percha and sealer and the treatment
\end{abstract}

\section{Introduction:}

The major challenges associated with endodontic treatment of teeth with open apices are achieving complete debridement, canal disinfection and optimal sealing of the root canal system. ${ }^{1}$ Absence of a natural constriction at the apical portion reduces the control to maintain the filling material confined into the root canals. ${ }^{2}$ In the absence of a natural apical constriction, the production of mineralized tissue in the apical region is important to create an apical barrier and allow 3dimensional adaptation of obturating material within the root canal system.

On this regard, calcium hydroxide has historically been used to establish apical closure by inducing apexification. This technique, first introduced by Kaiser and later spread by Frank ${ }^{2}$, allows hard tissue deposition at the end of the root. It restricts bacterial infection and establishes a suitable environment for periapical repair. ${ }^{3}$ Although calcium hydroxide apexification has a success rates in the mid- $90 \%$ range ${ }^{4}$, important disadvantages

a. Dr (Major) Md Abdul Hannan Sheikh, Classified Specialist in Conservative Dentistry \& Endodontist, CMH, SavarCantt.

b. Dr Abdul Kader Shaikh, Associate Professor, Department of Neurology, BSMMU, Dhaka

c. Dr Kamrunnahar, Asst Prof. MH Somorita Medical College, Dhaka.

d. Dr Sultana Parveen, Asst Prof. MH Somorita Medical College, Dhaka.

Address of Correspondence: Dr (Major) Md Abdul Hannan Sheikh, Classified Specialist in Conservative Dentistry \& Endodontist, $\mathrm{CMH}$, Savar Cantt. Email-drhannan65@gmail.com

Received: 29 March 2017

Accepted: 28 October 2017 was completed within 3 consecutive appointments. In twelve months follow up both the teeth were clinically and radiographically asymptomatic and the healing of the apical area was continued. The positive clinical outcome may encourage the future use of mineral trioxide aggregate (MTA) as an apical plug material in case of non-vital open apex teeth.

Key Words: Apical plug, non-vital tooth, open apex, mineral trioxide aggregate (MTA).

(J Bangladesh Coll Phys Surg 2017; 35: 196-199)

have also been associated with its utilization. The need of multiple appointments, the long period of time for treatment completion, susceptibility to fracture ${ }^{5}$ and coronal microleakage during treatment ${ }^{6}$ are some of the disadvantages which could be mentioned. Also, the formed barrier, although apparently calcified, is in fact porous and sometimes contains small amounts of soft tissues. $^{7}$

Recently, mineral trioxide aggregate (MTA) was proposed as a potential material for apical sealing of infected immature teeth. It prevents the extrusion of filling material and also decreases the apical leakage. MTA is composed of fine hydrophilic particles that set in the presence of moisture. ${ }^{8}$ As a material for perforation repair, MTA offers many favorable properties, including good sealing ability ${ }^{9}$, biocompatibility ${ }^{810}$, radiopacity, and moisture resistance. ${ }^{8}$ It is also capable of inducing the deposition of mineralized tissue, stimulating the regeneration of the dentin and providing satisfactory antibacterial activity ${ }^{8}$ Considering those properties, the use of MTA barriers for sealing the apical portion of immature teeth has been proposed, and has shown excellent results. ${ }^{3}$ The following case report demonstrates the treatment of a case of infected maxillary incisors teeth which presented wide apex sealed using MTA as apical plug.

\section{Case Report:}

An 11-year-old boy was referred to the Dept. of Conservative Dentistry and Endodontics of Bangabandhu Sheikh Mujib Medical University with the complaints of pain on upper anterior segment for 
one month. He had a history of trauma 5 yrs back. On clinical examination, there was no extraoral abnormality detected, but intraorally we found crown fracture with discolouration of maxillary incisors. Vitality tests show non-vitality of involved teeth. The teeth had pain on percussion and he couldn't chew food on that area for last few weeks. No swelling, sinus tract or mobility was detected. Radiograph revealed radiolucency on periapical area of the roots of the maxillary central incisors with open apices. The case was diagnosed as Periapical periodontitis with open apices of maxillary central incisors. Treatment plan was made as Apical plugging of maxillary central incisors using MTA followed by root canal obturation with GP point and sealer.

The treatment was performed using following protocol(Methodology):

Straight line large access cavity with round diamond bur (no\#4) to allow removal of all necrotic tissue. Canal debridemet with barbed broach and headstrom file. Copious irrigation with sodium hypochloride $(2.5 \%)$ and normal saline combinedly in the presence of high volumic suction. Working length was established as left centralincisor-19 mm, right central incisor $17 \mathrm{~mm}$. Both the teeth were prepared by standardized technique. After drying the canal with sterile cotton dressing, slurry of calcium hydroxide with normal saline placed in to the canal with lentulo spiral. The access was filled with cotton pellet and zinc oxide eugenol cement. Patient was advised to revisit after one week.

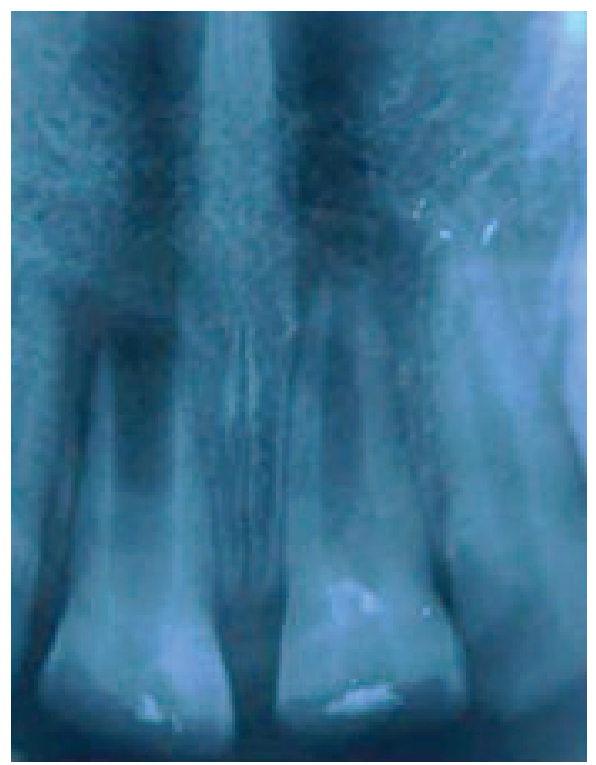

Fig.-1: Initial radiograph
On the next visit both teeth were symptomless. Temporary filling and cotton was removed. Calcium hydroxide was flushed with copious irrigation of sodium hypochloride, EDTA and sterile water with light instrumentation. The canals were dried with sterile cotton dressing and as it was dry, Pro-Root MTA (densply), grey variety mixed with distilled water to a creamy consistency in a proportion of $3: 1$ and introduced in to the canal with lentulo spiral $1 \mathrm{~mm}$ short of the radiographic apex and condensed into the apical 1/3 ( $4 \mathrm{~mm})$ by gentle packing with customized plugger which was confirmed with radiograph. A sterile cotton pellet moistened with sterile water was placed over the canal orifice and the access cavity was sealed with glassionomer filling.

After 72 hours, the hard set of MTA was confirmed and the remainder of the root canal was obturated with vertical condensation of gutta-percha. The access filled with glass-ionomer filling again. Post operative radiograph was taken to check the three dimensional obturation. After 1week both incisors were laminated with light cured composite restorative materials. The patient was advised to revisit for clinical and radiographic evaluations after 3, 6, 9, 12 months.

Follow up : After 12 months follow up, the teeth were clinically asymptomatic and radiographically healing of the apical area was continued.

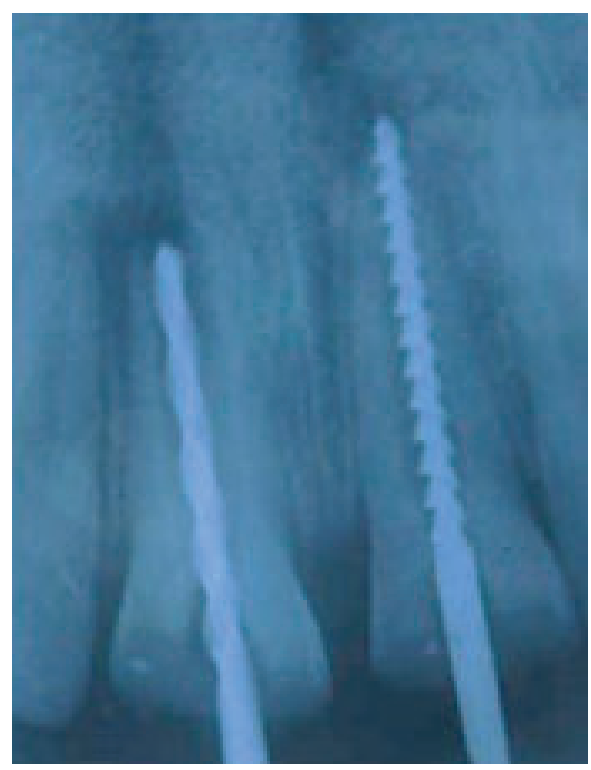

Fig.-2: Working length determination 


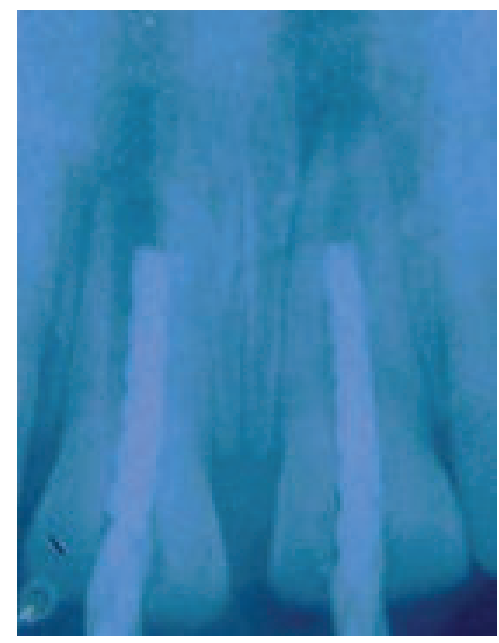

Fig.-3: Customized plugger

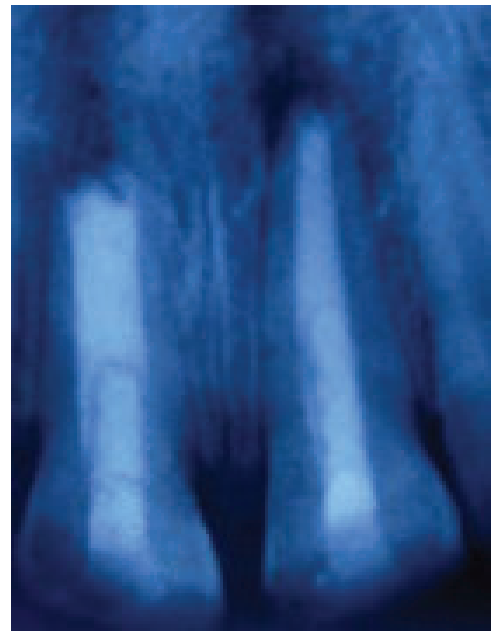

Fig.-5: Radiograph after 3 months

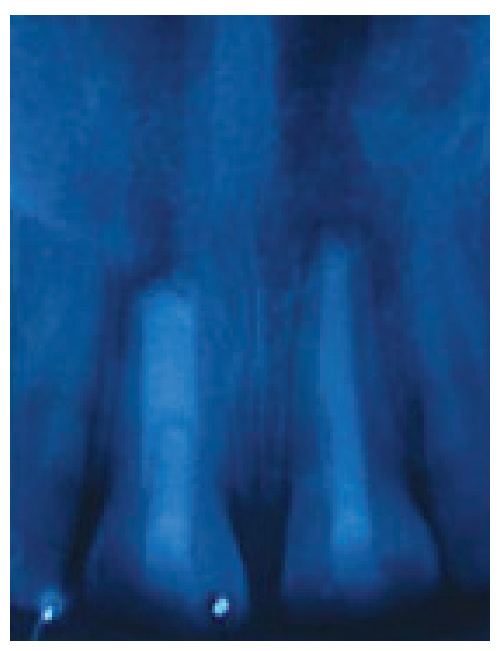

Fig.-7: Radiograph after 9 months

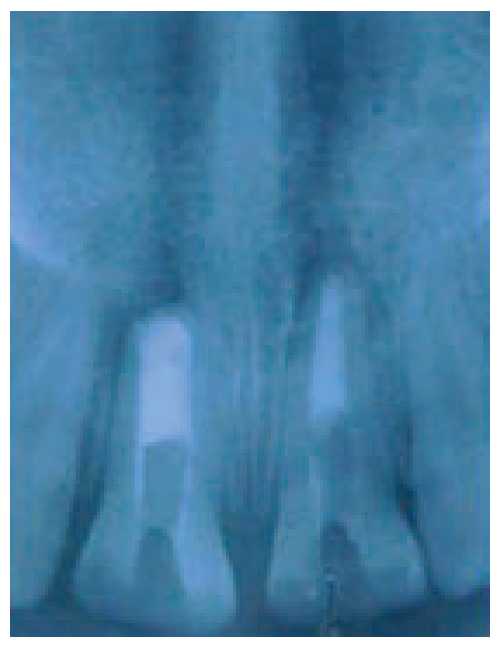

Fig.-4: Initial apical plugging

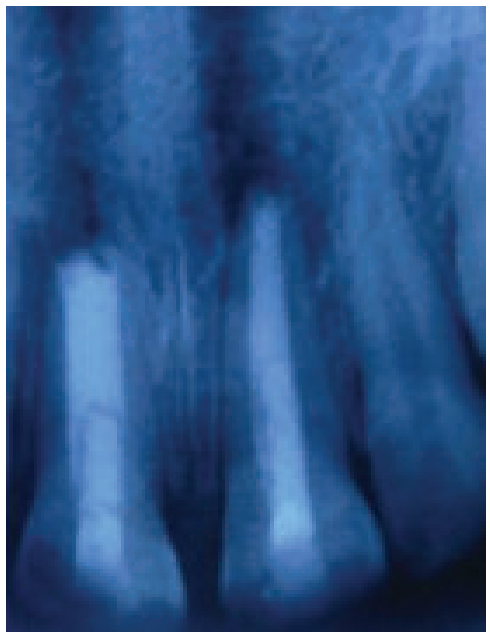

Fig.-6: Radiograph after 6 months

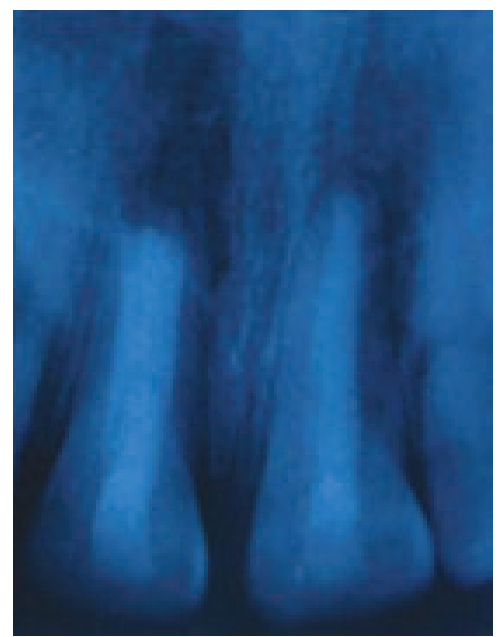

Fig.-8: Radiograph after 12 months 


\section{Discussion:}

The case reported herein demonstrated the applicability of MTA as a material used for apical plug in infected immature teeth. Although calcium hydroxide demonstrates satisfactory results on peri-apical repair and on obtaining an apical mineralized barrier, the use of MTA presents some advantages, such as the possibility of its placement in as little as one visit ${ }^{11}$ or after 1 or 2 applications of root canal dressings ${ }^{12}$, thus eliminating the waiting time required for calcium hydroxide apexification. This advantage is especially relevant because it has been proved that the placement of a permanent restoration after a short treatment time serves to increase fracture resistance of the immature teeth. ${ }^{14}$ Also, calcium hydroxide long term treatment may increase the risk of root fracture. ${ }^{13}$

In the present case report, it was chosen to use calcium hydroxide dressing before MTA placement. The use of this has been recently suggested, being supported by the advantages of keeping important properties of calcium hydroxide i.e, its tissue solving effect ${ }^{15}$ and its capacity of acting as a physical barrier preventing interappointment re-infection as well as increasing its antimicrobial effect. ${ }^{14,15}$ The improvement of chemical capacity of disinfection seems to be especially relevant in cases of non-vital immature teeth, which present several challenges for promoting mechanical cleaning and shaping. Characteristics such as the presence of thin and fragile lateral walls and the large volume of necrotic debris contained in wide root canals make the achievement of sufficient disinfection difficult.

The treatment results obtained in the present study might be also related to the fact that MTA is capable of maintaining the biological properties presented by calcium hydroxide. MTA forms calcium oxide when in contact with water, which when placed in contact with fluids of tissues forms calcium hydroxide, and triggers the same repair process in tissues. ${ }^{8110}$ In addition, MTA physical characteristics of expansion during the attachment assist to the achievement of the apical sealing. A 4-5mm apical plug is appropriate to resist displacement from the apex and to prevent infiltration of fluids in the canal. ${ }^{16}$

\section{Conclusion:}

MTA is a valid treatment option for cases of immature teeth, with the advantage of a shorter chair-side treatment, development of proper apical seal and excellent biocompatibility. The present clinical case confirms that MTA act as an apical barrier and can be considered to be a very effective material for managing non-vital teeth with open apices.

\section{References:}

1. AndreasenJO, Flores MT. Injuries to developing teeth. In: Andreasen JO, Andreasen FM, Andersson L, editors. Textbook and color atlas of traumatic injuries to the teeth. 4th ed. Copenhagen: Munksgaard; 2007. p. 542-76.

2. Frank AL. Therapy for the divergent pulpless tooth by continued apical formation. J Am Dent Assoc 1966; 72:78-93.

3. Holden DT, Schwartz SA, Kirkpatrick TC, Schindler WG. Clinical outcomes of artificial root-end barriers with MTA in teeth with immature apices. J Endod 2008; 34:812-7.

4. Cvek M. Treatment of non-vital permanent incisors with calcium hydroxide: I- follow up of periapical repair and apical closure of immature roots. Odontol Revy 1972;23;27-44.

5. Andreassen JO, Munksgaard EC, Bakland LK. Comparison of fracture resistance in root canals of immature sheep teeth after filling with calcium hydroxide or MTA. Dent Traumatol 2006;22:154-6.

6. Sauders WP, Saunders EM. Coronal leakage as a cause of failure in root canal therapy: a review. Endod Dent Traumatol 1994; 10:105-8.

7. Binnie WH, Rowe AHR. A histological study of periapical tissues of incompletely formed pulpless teeth filled with calcium hydroxide. J Dent Res 1973; 52:1110-6.

8. Torabinejad. M, Watson TF, Pitt Ford TR. Sealing ability of MTA when used as a root end filling material. J Endod 1993; 19:591-5.

9. Lee SJ, Monset M, Torabinejad M. Sealing ability of MTA for repair of lateral root perforations. J Endod.1993; 19:541-4.

I0. Holland R, Souza V, Nery MJ, Bernabe PFE, OtoboniFo JA, DezanJr E. Reaction of rat connective tissue to implanted dentin tubes filled with a white MTA. Braz Dent J. 2002; 13:23-6

I1. Witherspoon DE, Ham K. One visit apexification: technique for inducing root-end barrier formationin apical closures. Pract Proced Aesthet Dent 2001;13:455-60.

12. Shabahang S, Torabinejad M. treatment of teeth with open apices using MTA. Pract Periodontics Aesthet Dent 2000; 12:315-20.

I3. Andreasen JO, Farik B, Munksgaard EC. Long-term calcium hydroxide as a root canal dressing may increase rise of root fracture. Dent Traumatol 2002; 18:134-7.

14. Ercan E, Dalli M, Dulgergil CT. In vitro assessment of the effectiveness of chlorhexidine gel and calcium hydroxide paste with chlorhexidine against Enterococcus faecalis and Candida albicans. Oral Surg Oral Med Oral Pathol Oral RadiolEndod 2006;102:e27-31.

I5. Haenni S, Schmidlin PR, Mueller B, Sener B, Zehnder M. Chemical and antimicrobial properties of calcium hydroxide mixed with irrigating solutions. IntEndod J 2003;36:100-5.

16. Orosco FA, Bramante CM, Garcia RB, Bernadineli N, Moraes IG. Sealing ability of gray MTA AngelusTM, CPMTM and MBPC used as apical plugs. J Appl Oral Sci 2008; 16:50-4. 